\title{
A Case with Thyroid Cartilage Fracture after Sneezing
}

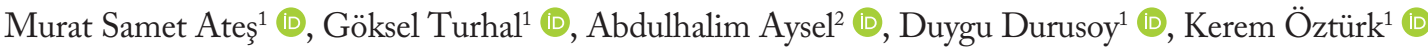 \\ Case Report $>{ }^{1}$ Department of Otorhinolaryngology, Ege University School of Medicine, İzmir, Turkey \\ ${ }^{2}$ Department of Otorhinolaryngology, University of Health Science, Bozyaka Training and Research Hospital, İzmir, Turkey
}

Abstract Non-traumatic laryngeal injuries are unusual occasions. In the medical literature we found only six reports of cases that had laryngeal injury after sneezing. We report a case of a 34-year-old man diagnosed with thyroid cartilage fracture after a strong sneeze. In physical examination, edema and hematoma were seen in the right vocal cord and the right band. Computed tomog- raphy scan revealed an anterior thyroid cartilage fracture without separation. Antibiotics and steroids were administered. This is a very rare entity and the seventh case reported in the literature. Ear Nose Throat specialist should be aware of this situation.

Keywords: Larynx, thyroid cartilage, fracture, sneezing, dysphonia
ORCID iDs of the authors: M.S.A. 0000-0003-4419-0662 G.T. 0000-0003-0020-1921; A.A. $0000-0001-8584-308 X$ D.D. $0000-0003-3012-6678$ K. $0.0000-0003-2754-4166$.

Cite this article as: Ateș MS, Turhal G, Aysel A, Durusoy D, Öztürk K. A Case with Thyroid Cartilage Fracture after Sneezing. Turk Arch Otorhinolaryngol 2020; 58(3): 197-9.

\section{Corresponding Author:} Murat Samet Ateş, muratsametates@gmail.com Received Date: 18.03 .2020 Accepted Date: 19.05 .2020

Content of this journal is licensed under a Creative Commons Attribution 4.0 International License. Available online at www.turkarchotolaryngol.net (c) (i) $\$$

\section{Introduction}

Sneezing is a reflex mechanism that can occur as a result of irritants stimulating the nasal mucosa. Histamine release occurs as a result of stimulation in the nasal mucosa against mucous residues, pathogenic microorganisms or allergen stimuli (1). The $5^{\text {th }}$ cranial nerve receptors sense the stimulus and send signals to the brainstem, and deep inspiration takes place to increase the pressure against a closed vocal cord. The sudden opening of the vocal cord under subglottic pressure sends the pressure along the upper airway. At the same time the tongue rises and the air is expelled from the nose at about $100 \mathrm{~m} / \mathrm{s}$ (2). Voluntary closure of the lips and the nasal airway causes an increase in pressure up to 20 times of the normal sneezing. This pressure can spread to the other parts of the body, leading to various barotraumatic injuries (2).

To our knowledge, external laryngeal trauma is the most common cause of traumatic laryngeal injuries. Laryngeal fracture is an uncommon injury but can be life-threatening. Laryngeal fracture can be secondary to blunt or penetrative trauma, or it very rarely can be non-traumatic. Blunt trauma is seen more frequently than penetrating injury. Dis- placed laryngeal cartilages can cause major problems in terms of airway patency and airway protection, swallowing and phonation. Non-traumatic thyroid cartilage fracture especially after sneezing is extremely rare and only six cases have been reported in the medical literature. In this study, we report the case of a 34-year-old man who had thyroid cartilage fracture after a strong sneeze.

\section{Case Presentation}

The 34-year-old male presented to the Ear, Nose and Throat (ENT) Department with dysphonia, odynophagia and cervical discomfort without dyspnea or dysphagia following a strong sneeze. $\mathrm{He}$ denied any history of external trauma, operation or intubation. He was otherwise healthy without contributory medical history.

Physical examination showed normal oropharynx. Edema and hematoma of the right true vocal cord and the right ventricular band was seen in endoscopic examination (Figure 1). The mobility of the vocal cords was normal. The vocal cords could completely close and air passage was sufficient. A small subcutaneous emphysema was revealed on cervical palpation and no external trauma evidence was found (Figure 2). 


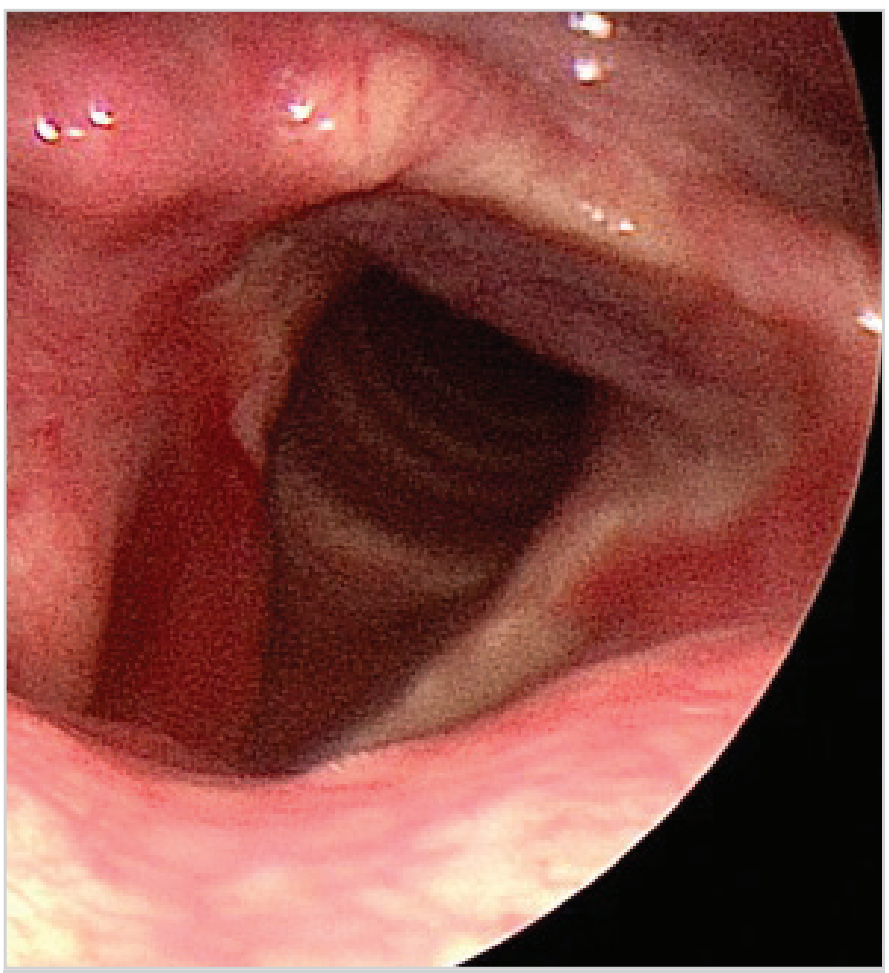

Figure 1. Hematoma of the right vocal cord and ventricular band

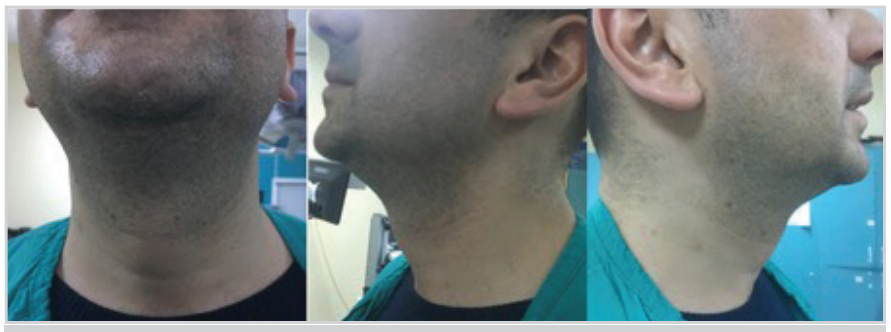

Figure 2. The patient had no external trauma findings

Cervical Computed Tomography (CT) scan revealed a longitudinal paramedian split of the thyroid cartilage without separation and displacement, right vocal cord and ventricular band edema, and subcutaneous emphysema in the anterior zone of the neck, on bilateral sides of the thyroid cartilage and surrounding the thyroid gland (Figure 3).

The patient was admitted for treatment and observation. Intravenous antibiotic and corticosteroid therapy were administered for seven days, and absolute voice rest was applied.

\section{Main Points}

- Non-traumatic thyroid cartilage fracture especially after sneezing is extremely rare.

- It is possible that these patients had more thyroid cartilage ossification than their peers.

- ENT specialists should be aware of this condition in the presence of dyspnea, dysphonia, odynophagia, cough and dysphagia after sneezing.

- Comprehensive physical examination is required by inspection and cervical palpation, laryngeal endoscopy and imaging tests, especially cervical CT.
Edema of the right vocal cord and hematoma of the right band regressed in the follow-up period. At seven days the clinical symptoms had completely disappeared and otorhinolaryngologic examination became normal. The patient was discharged with a prescription of oral antibiotic and steroid for two weeks. The patient was followed-up for six months. All necessary written informed consents for both the treatment and the study were obtained from the patient.

\section{Discussion}

The most common cause of laryngeal cartilage fracture is external trauma. Thyroid cartilage fracture without a trauma history, especially after sneezing, is extremely rare. Only six case reports were found in the literature (3-8). All reported patients were aged between 30 to 50 , and all were male. All except one who refused to be treated and recovered spontaneously, achieved complete recovery with conservative treatment (6). The conservative treatment included corticosteroid therapy, absolute voice rest, and antibiotic therapy in some case reports.

Schaefer and Close (9) classified thyroid cartilage fractures in 1989 as:

- I: minor endolaryngeal hematoma or laceration absence of a detectable fracture,

- II: edema, hematoma or minor mucosal destruction without exposed cartilage and non-displaced fracture on CT scan,

- III: massive edema, large mucosal laceration, exposed cartilage and stable displaced fracture,

- IV: more severe injuries than group 3 and unstable displaced fracture.

In the case of I-II, it is recommended that the patient be hospitalized for observation and treatment, for intravenous antibiotics, corticosteroid therapy and pulse-oximetric control. In the case of III-IV, an emergency tracheotomy is required to provide respiratory clarity, endoscopic and surgical studies with general anesthesia are recommended for cartilage fracture repair. Our patient had a type II injury according to Schaeffer's classification.

Sneezing accumulates the air in the subglottic zone against a closed glottis during expiration, causing a sudden increase in subglottic pressure. Then the glottis opens suddenly, causing high-velocity air to escape from the mouth and nose. During sneezing, the total speed of the air potentially rises above 100 $\mathrm{m} / \mathrm{s}(2)$.

Fenig et al. (10) suggested that these patients might have an abnormality in thyroid cartilage mineralization and ossification process. They also point out that this process differs between male and female subjects and therefore can explain the male dominance seen in these case reports. Male thyroid cartilage ossifies earlier and more extensively than female thyroid cartilage. It is possible that patients in these reports had more thyroid cartilage ossification than their peers. Alternatively, ossified cartilage areas adjacent to cartilage that have not yet been ossified can create areas susceptible to fracture and separation with a sudden increase in upper airway pressure (7). 


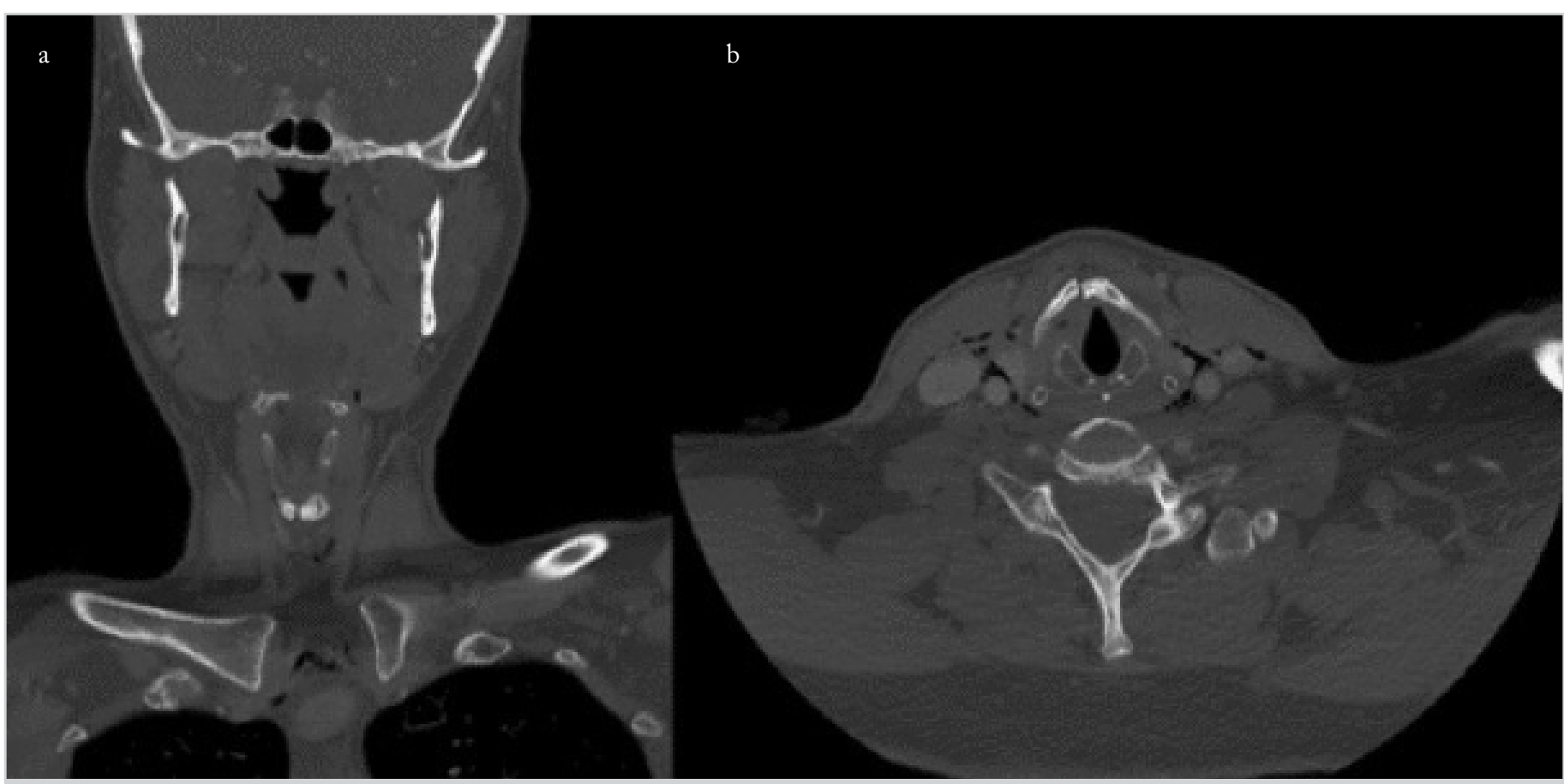

Figure 3. a, b. (a) Coronal and (b) axial CT scan showed longitudinal paramedian fracture of the anterior thyroid cartilage

When we reviewed the scientific literature, we have found six similar case reports. We report here the seventh case of thyroid cartilage fracture as a result of sneezing.

\section{Conclusion}

Although a rare entity, experienced physicians and ENT specialists should be aware of the possible association between sneezing and laryngeal barotrauma. We have to suspect this condition in the presence of dyspnea, dysphonia, odynophagia, cough and dysphagia after sneezing. Comprehensive physical examination is required by inspection and cervical palpation, laryngeal endoscopy and imaging tests, especially cervical CT.

Informed Consent: Informed consent was obtained from the patient.

Peer-review: Externally peer-reviewed.

Author Contributions: Concept - A.A.; Design - A.A.; Supervision - K.Ö.; Funding - G.T.; Materials - G.T.; Data Collection and/or Processing - D.D.; Analysis and/or Interpretation - D.D.; Literature Search - M.S.A.; Writing - M.S.A; Critical Reviews - K.Ö.

Conflict of Interest: The authors have no conflicts of interest to declare.

Financial Disclosure: The authors declared that this study has received no financial support.

\section{References}

1. Setzen S, Platt M. The dangers of sneezing: a review of injuries. Am J Rhinol Allergy 2019; 33: 331-7. [Crossref]

2. Rahiminejad M, Haghighi A, Dastan A, Abouali O, Farid M, Ahmadi G. Computer simulations of pressure and velocity fields in a human upper airway during sneezing. Comput Biol Med 2016; 71: 115-27. [Crossref]

3. Quinlan PT. Fracture of thyroid cartilage during a sneezing attack. Br Med J 1950; 1: 1052. [Crossref]

4. Beato Martínez A, Moreno Juara Á, López Moya JJ. [Fracture of thyroid cartilage after a sneezing episode] (in Spanish). Acta Otorrinolaringol Esp 2007; 58: 73-4. [Crossref]

5. Faden DL, Elackatuu A, Platt M. The "closed-airway sneeze": an unusual cause of laryngeal fracture. Otolaryngol Head Neck Surg 2011; 145: 515-6. [Crossref]

6. Forner D, Phillips T, Brown T. Laryngeal injury and subcutaneous emphysema caused by an episode of sneezing: a rare case treated with observation alone.J Laryngol Voice 2016; 6: 21-4. [Crossref]

7. Reuther MS, Weissbrod PA. Voice change, odynophagia, and neck pain following a sneeze. JAMA Otolaryngol Head Neck Surg 2017; 143: 89-90. [Crossref]

8. Byrne B, Tillman R, Johansson M. Laryngeal fracture after a stifled sneeze: a case report.J Emerg Med 2020; 58: 97-8. [Crossref]

9. Schaefer SD, Close LG. Acute management of laryngeal trauma. Update. Ann Otol Rhinol Laryngol 1989; 98: 98-104. [Crossref]

10. Fenig M, Strasberg S, Cohen JC, Almadi R, Gold M. Laryngeal fracture after coughing. Am J Emerg Med 2013; 31: 1421.e1-e3. [Crossref] 